\title{
LA ONOMÁSTICA Y LA TOPONIMIA COMO SEÑALES EN EL PROCESO DE CONFORMACIÓN DE IDENTIDAD DE “AGUA FRÍA”, EN LA NOVELA TEMBLOR DE ROSA MONTERO
}

\author{
Larissa Castillo Rodríguez
}

\begin{abstract}
RESUMEN
El artículo analiza la función de la onomástica y la toponimia en el proceso de conformación de identidad de la joven protagonista de la novela Temblor: "Agua Fría", quien emprende una búsqueda con el fin de encontrar la verdad anhelada. Las señales, en este caso, onomásticas y toponímicas, se vinculan para descifrar una serie de dudas que la joven se plantea a lo largo de su periplo.

Palabras clave: onomástica, toponimia, conformación de identidad, señales, narrativa española.
\end{abstract}

\begin{abstract}
The Onomastics and Toponimy when building the main female character identity, in the novel "Temblor", who is named "Agua Fría". She starts a journey pursuing her desiring truth. The onomastic and toponimic clues are mixed up to answer questions the female character states along her journey.

Key words: Onomastics, toponimy, identity construction, clues, Spanish narrative.
\end{abstract}

\section{Introducción}

La novela Temblor, publicada en 1990, relata la historia de "Agua Fría", una joven huérfana que debe emprender un viaje lleno de retos y desafíos para encontrar su propia identidad. El análisis de este artículo surge debido a que, a lo largo de todo el texto, se presentan "señales" cuya función es guiar, o bien, probar a la protagonista, quien se encuentra buscando

Licda. Larissa Castillo Rodríguez. Profesora de la Escuela de Ciencias del Lenguaje. Instituto Tecnológico de Costa Rica.

Correo electrónico: laricastillo@gmail.com

Recepción: 23- 10- 2009

Aceptación: 3- 03- 2010 
su camino, "su norte”. Estas "señales” serán entendidas como aquellos elementos -toponímicos u onomásticos- indicadores de las pruebas ya culminadas o por superar.

De esta manera, la función toponímica-onomástica será la señal que dará paso a la siguiente prueba, ya que cada espacio o personaje involucrado con "Agua Fría" no está puesto al azar, sino que, desde el "nombre" se establece una relación con ese camino para encontrar la identidad.

Debido a lo anterior, lo que se pretende demostrar es cómo la onomástica se encuentra ligada a la búsqueda de identidad de "Agua Fría" y cómo ella culmina su recorrido gracias a la presencia de ciertos personajes y espacios que dejan huella en su vida.

Por otra parte, es importante recalcar que cada nombre es un referente dentro del contexto que enmarca a la joven. Así, por ejemplo, cada región está constituida por personajes que definen las particularidades de vida. Por lo tanto, "Agua Fría” descubre que la existencia no es más que una amalgama de posibilidades otorgadas por el destino, un destino a veces incierto, a veces certero.

\subsection{Consideraciones teóricas}

La onomástica literaria trata del estudio de los nombres propios y el significado, explícito o implícito, que adquieren dentro del texto.

Para Eugène Nicole (1983), el nombre propio es importante; es un signo que define al personaje y, por ende, su comportamiento. Para según José Luis Alonso (1982), los nombres gozan de un significado y muchos escritores, conscientes de esto, han señalado nombres sugerentes a los personajes de las obras literarias. Sin embargo, en otros casos, la evidencia de su significado es difícil de descubrir, pero se sabe que ahí está, y parte de la importancia y función del personaje dentro del texto está ligado al nombre.

Justo como lo señala Nicole (1983), la onomástica literaria muestra el valor semántico de los referentes del personaje; por eso, afirma que el proceso de selección de nombres es muy importante, pues se trata de precisar las condiciones específicas del nombre propio, en el campo que le es inherente: la sistemática del texto.

El nombre propio precisa al personaje dentro de su contexto, es decir, lo ubica dentro de una red, la cual define la estructura social a la que pertenece. Por lo tanto, el nombre se constituye en un signo porque es necesario incorporarlo dentro de un sistema para que pueda ejercer la función de identificar, clasificar o significar, como lo manifiesta Nicole (1983).

También es importante mencionar que, además de la función narrativa destinada al personaje por medio del nombre, éste le da significado a la novela, en tanto que muestra la apariencia de "propiedad" que ya de por sí su uso frecuente lo tiene.

Los nombres empleados en narrativa aseguran la identificación de los miembros del grupo, así como la continuidad de esta referencia en el proceso de la narración.

Desde un punto de vista narrativo, la identificación acompañada de varios rasgos sémicos, funda el relato y orienta la lectura en la expectativa de un destino. Por eso, elaborar un estudio onomástico supone realizar observaciones puntuales por medio de la etimología y la semántica: las dos ciencias que están estrechamente relacionadas con este campo de investigación. Nicole (1983) afirma que la onomástica literaria aporta aclaraciones con el fin de comprender en su totalidad el signo o el texto del que la onomástica forma parte.

l' onomastique littéraire qui est, à l' étude du fonctionnnement textuel des noms propres, ce que l' onomastique est à la thérie du Nom: un champ relativemen restreint d’ observations pontuelles visant à metre en évidence, souvent à travers l'étimologie, la valeur sémantique des référents du personaje ou du lieu chez des auters réputés particulièrement sensibles au choix de leurs signifiants. ${ }^{1}$ (Nicole 1983: 233) 
Por otra parte, Derridá, citado por Nicole (1983), plantea que "Un texte n' existe, ne résiste, ne consiste, ne refoule, ne se laisse lire ou écrire que s' il est travaillé par l' illisibilité d' un nom progre"2 (1983: 234), por lo que la onomástica dentro del texto literario adquiere un valor fundamental en tanto su funcionamiento permite aclarar la presencia y desarrollo de los personajes.

Asimismo, el texto emplea procedimientos del sistema apelativo: nombres comunes de títulos y términos de parentesco, por ejemplo; entonces, se forma la significación social y la designación del personaje del sistema del texto literario. En ese sentido, la onomástica literaria puede utilizar connotaciones que lleven a establecer una asociación de elementos culturales o lingüísticos cuyo valor sea imprescindible para entender el funcionamiento del personaje o del espacio en el que se desarrolla ese personaje.

Ahora bien, tras identificar los postulados más relevantes de la onomástica literaria, es necesario tomar en cuenta que Temblor está constituido por espacios que marcan cada una de las etapas del viaje de "Agua Fría"; por eso, resulta pertinente aludir a la toponimia dentro del estudio onomástico, pues permitirá la justificación del vínculo entre el personaje y el lugar.

Flor Garita (2001) afirma que la terminología geográfica no depende solamente de los intereses culturales, sino que además está influenciada por la estructura lingüística. Por lo tanto, la toponimia se refiere a la vida total del ser humano, tanto en su esfera individual como en la colectiva, y para ello "echa mano" de las posibilidades designativas que el léxico total de la lengua le brinda.

Garita (2000) propone que para asignarle un nombre a un lugar, la gente se enfrenta al hecho de crear el topónimo siguiendo dos parámetros: 1) tomar nombres comunes, sustantivos o grupos nominales de diversos tipos y 2) usar un vocablo que ya existe como nombre propio y dárselo a ese topónimo. Refiriéndose a este punto 2, la investigadora arguye que la influencia extranjera -en Costa Rica- tiene un papel preponderante en este proceso de designación de nombres, porque los primeros inmigrantes repitieron nombres de sus lugares de origen, o bien, los pobladores admiraban algún lugar extranjero y decidieron nombrar el accidente geográfico o poblado. Sin embargo, para efectos de nuestro análisis serán tomadas ambas variantes.

El acto de nombrar no es una cuestión anodina. Las palabras tienen la magia de producir efectos en quien las pronuncia; por eso, cada uno de los nombres, sean propios o de otra índole, responden a una motivación del hablante.

El problema de la nomenclatura (Garita 2001) está vinculado al significado; además, detrás de las expresiones lingüísticas se encuentra una realidad extralingüística, pues el lenguaje permite comprender la realidad y, gracias a él, se divide, se agrupa y se clasifica todo cuanto nos rodea.

Por otra parte, si se toma en cuenta la relación cultura-lenguaje, se obtiene que cada una de las categorías culturales se expresan léxicamente, no en forma automática, sino selectiva. No obstante, hay que considerar que esta relación genera un problema, porque, como afirma Garita (2001): "en una cultura particular, una lengua sirve como especie de "metalenguaje", un modo de comunicar mucho, pero no todo acerca de la cultura" (2001: 75).

Se parte del hecho de que los intereses culturales son el factor primordial de la terminología, pero la selectividad afecta los tipos de términos, pues no se pretende asumir que todos asimilamos de igual forma una lengua, o bien, contamos con la misma motivación en el momento de nombrar.

Sin embargo, a pesar de esa problemática, los nombres geográficos llevan consigo la vida cultural y la línea de desarrollo a la que pertenece cada pueblo: porque son la expresión del carácter mental de cada pueblo. Por eso, la forma de cada lengua puede limitar el número de términos. 


\section{La onomástica y la toponimia en la conformación de identidad de "Agua Fría"}

El texto desde el título, Temblor, evidencia un estado de movimiento, cuyas ondas pueden expandirse dependiendo de su duración y profundidad. Si esto se asimila al comportamiento de la joven heroína, se obtiene que el temblor constante que siente, es un estado de duda - propio de una trayectoria rumbo a lo desconocido-; un estado de temor, al aceptar una responsabilidad sin pedirla; y un estado de insatisfacción consigo misma y con el contexto, de ahí que la duración de ese movimiento sea prolongada, e incluso, profunda, como algunas veces sucede con estos fenómenos naturales.

Los nombres, en este caso, determinarán la función del personaje y el lugar en donde se encuentre "Agua Fría" estará asociado a su tipo de aprendizaje y a la prueba por enfrentar. Se trata de una relación entre el nombre del personaje y el nombre del espacio que propicia la señal para la siguiente prueba de la protagonista. Ya no serán las acciones o los personajes por sí solos quienes brinden un camino hacia "la verdad", sino que se deberá tomar en cuenta la onomástica y la toponimia para descubrir este "norte", el camino conformador de su identidad.

En el caso de la protagonista, ella goza de un nombre muy particular que conlleva un análisis desde su carácter simbólico: el agua y el comportamiento de ella en su viaje hacia "lo desconocido". De esta forma, ella también participa en los procesos fundamentales para el desarrollo de la existencia, por lo que ya la onomástica de "Agua Fría" trae consigo la esencia de la vida.

Al cambiar de nombre en el momento de ser bautizada, "Agua Fría" adquiere mayor responsabilidad. Se trata de su propio reconocimiento y la marca del mentor en la adquisición de una identidad y compromiso determinados. El nuevo nombre, "Agua Fría", implica la incorporación a un contexto con el signo que le permitirá ampliar su conocimiento y alcanzar su madurez. Las características del agua son amplias. Se proponen las facultades purificadoras, la sabiduría, la gracia y la virtud (Chevalier, 2003: 53) como aspectos presentes en el comportamiento de la joven.

Según Chevalier (2003), el agua reintegra y regenera. Por lo tanto, a manera de esquema, el momento bautismal se visualizaría así:

\section{Talika $\longrightarrow$ baño $\longrightarrow$ bautismo $\longrightarrow$ "Agua Fría” $\longrightarrow$ reintegración $\longrightarrow$ regeneración}

Y una vez reintegrada a ese mundo, Corcho Quemado, su mentora, cumple con su deber, precisamente al dejar a la joven libre para iniciar su camino, porque el proceso de búsqueda de identidad se desarrollará amalgamando todos los elementos y acontecimientos de la heroína, los cuales no están puestos al azar, sino que se presentan para someterla a prueba y formarla con un carácter independiente.

José Luis Alonso (1982) señala la función y el comportamiento de los personajes ligado al nombre. Cada uno evidencia una labor dentro del texto, que asociada al nombre permite esclarecer su participación; así por ejemplo, en Temblor la nominación va paralela al proceso de conformación de identidad de "Agua Fría".

En primera instancia, la nominación espacial está distribuida de acuerdo con la evolución de la heroína. Se parte del lugar más cerrado -Palacio fortaleza de la Ley- a los más 
abiertos, como el Desierto o Renacimiento, cada uno respondiendo a diferentes formas de vida y aprendizaje. Su nombre es per se simbólico.

En segunda instancia, la nominación de los personajes se relaciona con los diferentes aprendizajes en cada uno de los lugares que visita, por un lado, y con la posición de ese personaje ante la existencia, por otro. Tal es el caso de Respy (Respetuoso Orgullo de la Ley) y Mo (Momento de Duda).

El viaje de aprendizaje le concede a la joven intercambiar experiencias con personajes muy particulares. Se destacarán precisamente Pedernal, Respy y Mo, tres varones que se convierten en sus aliados en la lucha por buscar la verdad. El siguiente esquema resume las características que simbolizan a cada uno de estos jóvenes.

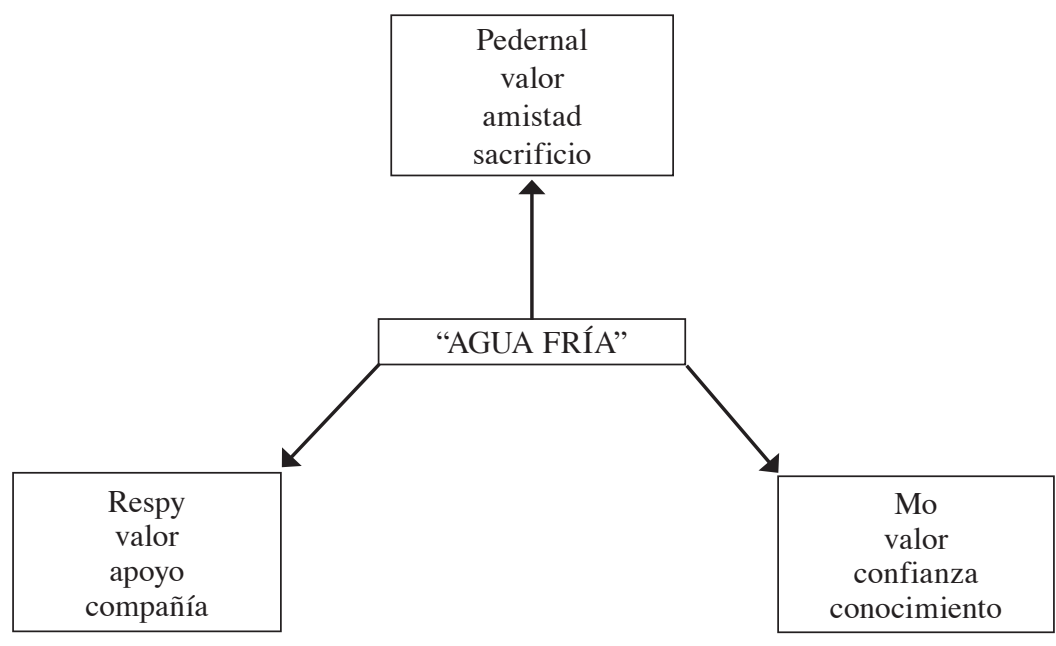

Esquema 1. Características simbólicas de Pedernal, Respy y Mo

Pedernal es el compañero del Talapot. Su nombre hace referencia a una roca sedimentaria constituida por sílice amorfo. El vocablo se encuentra asociado a las calizas, rocas sedimentarias formadas por carbonato de calcio, depositadas en aguas profundas. Su color es negro o en tonos oscuros de azul, gris o pardo; en general significan soporte y solidez.

La presencia de este personaje es clave en la estancia dentro del palacio. El comportamiento de Pedernal es duro, fuerte, evidenciando valor para soportar los crueles castigos y el rígido aprendizaje. Como Perdernal y "Agua Fría” se someten al mismo esquema de aprendizaje en el Talapot, será él joven quien aliente a "Agua Fría" a continuar el viaje, sacrificando su propia vida por ella

\footnotetext{
- ¡Huye, “Agua Fría”, huye! - oyó gritar a Pedernal, reducido de nuevo por los sacerdotes [...] "Agua Fría" se fue recuperando y comenzó a llorar. Lloraba por Pedernal, su amante, y por Pedernal su amigo de la infancia, aquel niño que había sido su único cobijo en los últimos años. A esas alturas el muchacho ya debía de haber muerto [...]. (Montero 2000: 89, 99)
}

Respy, por su parte, es quien acompaña a la heroína en su trayectoria hacia Renacimiento. La relación que se origina con "Agua Fría" se debe a la huida del Talapot; ambos son renegados, por lo que necesitan mantenerse al margen de la ciudad, de lo contrario, una posible aprehensión les estaría costando la vida. Adicionalmente, se apoyan en los diversos conflictos que se encuentran en el camino. 
El onomástico Respy, síntesis de Respetuoso Orgullo de la Ley, lleva implícito un simbolismo. Paradójicamente, el Anterior o su mentor, le otorga a este joven un nombre que se aleja de lo que en verdad es este chico: Respy huye de la Ley establecida en Magenta. Además, no se siente orgulloso de llamarse así, por lo que decide autonombrarse Respy en lugar de "Respetuoso Orgullo de la Ley", pues en última instancia lo que haría sería respetar la ley. Se trata, entonces, de una inversión onomástica de quien es subversivo.

\footnotetext{
[...] Respetuoso Orgullo De La Ley... Horrible. En fin, puedes llamarme Respy. Todo el mundo me conoce de ese modo. [... ]El rito de salutaciones no es más que una ceremonia en honor de los que ya se han muerto. Admito que lo de revivir a nuestros Anteriores a través del recuerdo es una costumbre hermosa, pero se da la circunstancia de que yo odio y desprecio a mi Anterior (Montero 2000: 24)
}

La relación de "Agua Fría” con Respy facilita la continuación del viaje. Respy, al igual que Pedernal, le brinda valor y coraje en su búsqueda incesante hacia el Norte. Se puede vislumbrar, entonces, cómo durante este proceso de formación de identidad, el sujeto en busca de la verdad ( "Agua Fría"), se encuentra con una serie de aliados y oponentes que entorpecen o aligeran el objetivo primordial. "Agua Fría" es una joven valerosa y tenaz que afronta las adversidades y sale victoriosa de ellas. Por eso, al estrechar los lazos de amistad con Respy se percata de la importancia del joven en su vida. Es Respy quien acompaña a "Agua Fría” en el trayecto del Desierto y es él, "Respetuoso" y "Orgulloso", quien deja a la joven en el umbral de Renacimiento, el pueblo que la acogerá y le enseñará a valerse por sí misma.

Ahora bien, Mo, el último de los tres varones, se convierte en un mentor para la joven y le enseña a cazar y a luchar por la supervivencia. Mo es un diminutivo de Momento de Duda. El nombre sitúa al personaje con un comportamiento al principio extraño, justo al connotar duda y misterio. "Agua Fría" es la encargada de remover en Mo sentimientos enterrados hace muchos años. Una vez más, la joven actúa movida por su condición vital: Agua, cuyo aporte es "reintegrar" y "purificar" el Momento que por tanto tiempo ha estado invadido por la Duda de entregarse.

Era un hombre (Mo) de unos treinta años, fuerte, atlético, con la piel curtida y arrugada por el trabajo a la intemperie. [...] un hombre en extremo silencioso casi arisco [...] Pasaba así sus días "Agua Fría", entre la caza, las labores de la granja, los estudios y el dulce y controlado incendio de los brazos de Mo (Montero 2000: 133, 138, 148)

Los momentos juntos son de gran aprovechamiento (Momento). Superada la duda de "Agua Fría", el tiempo y el espacio pasan a ser aliados en la interrelación de estos dos personajes (Duda).

Entonces, Pedernal, Respy y Mo son los hombres que participan en el proceso de conformación de identidad y la relación que "Agua Fría" desarrolla con ellos ofrece ventajas en cada una de las etapas de conocimiento posteriores -tómese en cuenta que la joven está acostumbrada a vivir en un régimen dominado por mujeres-. Es hasta su estancia con los Uma que las reglas cambian; no obstante, esto se desarrollará más adelante.

Por otra parte, "Agua Fría", a lo largo de su recorrido, conoce una serie de lugares y personajes, en su mayoría mujeres. Todos ellos cumplen una función: aportan pistas, aprendizaje o experiencia para que la protagonista alcance su objetivo.

Cada espacio ofrece algo diferente que la heroína irá incorporando a su vida. Se trata de formar un sujeto con características para alcanzar una madurez y un estado de completud. Para ello, las señales de los nombres facilitarán esa labor y la propia joven aprenderá a distinguir las diversidades del contexto. 
Los lugares están habitados por personajes muy particulares, respondiendo precisamente a la especificidad de ese espacio. El siguiente esquema muestra cuál será esa distribución para luego ser analizada.

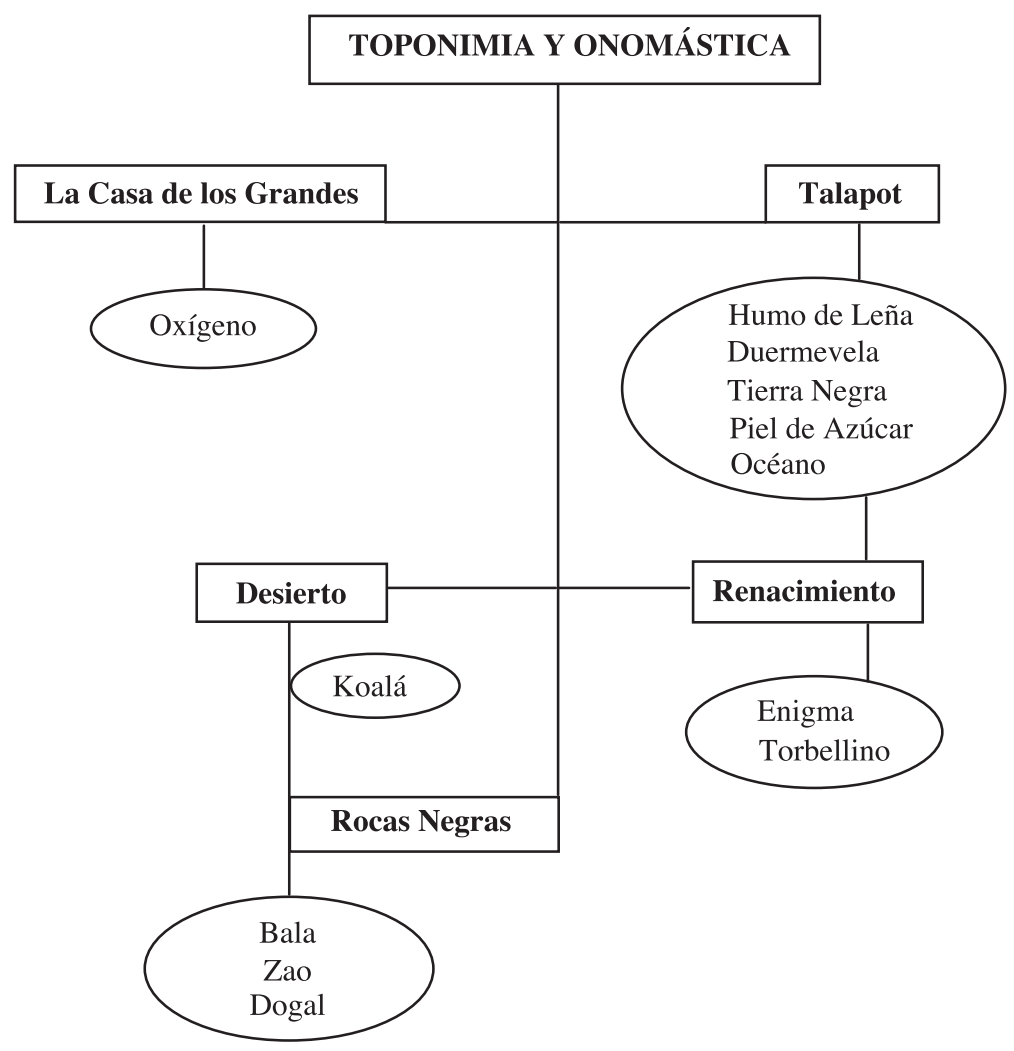

Esquema 2. Distribución de los habitantes de Temblor, según su espacio

Como se ejemplificó anteriormente, la onomástica literaria se refiere al estudio de los nombres propios y el significado que adquieren dentro del texto. Además, generalmente, el nombre de los personajes se encuentra estrechamente relacionado con el del espacio y, en virtud de este vínculo, se establecerá el diálogo entre el nombre propio (onomástica) y el nombre del lugar (toponimia), ${ }^{3}$ como vectores en el proceso de conformación de identidad.

Temblor es una novela conformada por una cantidad de espacios y personajes, cuyos nombres son referentes del personaje principal. El texto narra la historia de una heroína en proceso de formación y la onomástica y la toponimia desempeñaran una función referencial en esa búsqueda de la verdad.

Nicole (1983) señala que la onomástica literaria muestra el valor semántico de los referentes del personaje; por eso, afirma que el proceso de selección del nombre es muy sensible, pues se trata de precisar las condiciones específicas del nombre propio. La selección de personajes en Temblor establece un vínculo estrecho con el espacio en el que se encuentran (nuevamente onomásticatoponimia). Así, el lugar cuenta con características que definen el estilo de aprendizaje y el habitante no es ajeno a ese tipo de educación. De ahí que los nombres de los personajes funcionen como referentes mostrando habilidades inherentes, propias de ese nombre y su lugar de contexto. 
Ahora bien, cinco son los territorios que el texto ofrece como espacios de conocimiento e indicadores del proceso de conformación de identidad de la heroína: Talapot, La Casa de los Grandes, Renacimiento, el Desierto y Rocas Negras, que si bien son analizados a la luz de la onomástica, responden a especificidades toponímicas necesarias para que "Agua Fría" logre su objetivo.

\subsection{Talapot}

La cuestión de asignar una denominación se convierte en un efecto imperceptible en la conciencia de quien la emplea. En el caso de un topónimo, como apunta Garita (2001), refleja la vida y la línea de desarrollo a la que pertenece cada área cultural. De ahí que, en el caso de nuestro texto de análisis, se cuente con una serie de nombres geográficos referentes a la forma de ser de cada pueblo.

El Talapot corresponde al Palacio-Fortaleza de la Ley. Es un espacio completamente cerrado cuyo estilo de aprendizaje está militarizado. El objetivo del Talapot es enseñar la hipnosis a las mujeres que han sido destinadas a ser sacerdotisas cobalto. Este castillo responde a una estructura matriarcal rígida y cruenta; por lo tanto, si emitimos un juicio acerca de la asociación semántica de la palabra, se diría que Talapot remite a "talar". Con ese significado se podría establecer una relación con los términos, "arrasar", "destruir", "devastar" y "exterminar", pues se trata de cada uno de los ideales inculcados por los tutores.

"Agua Fría" y Pedernal sufren la estadía en el castillo. Su cerebro es "lavado" talando por completo su estilo de vida anterior: "En el Talapot disciplinarán tu mente y te enseñarán todas las respuestas. Y entonces comprenderás que todo lo que hacemos, absolutamente todo, es por amor" (Montero 2000: 39).

La idea de presentar un espacio de esta índole como primera etapa de aprendizaje del viaje responde a una estrategia dentro de un proceso. No se logrará la superación de las siguientes pruebas, sino se tiene dominio de sí mismo; por eso, es vital que "Agua Fría” se interne allí.

La adquisición de la hipnosis la facultará para desenvolverse en situaciones complicadas y por qué no, para un mayor conocimiento de sí misma. Recuérdese que este procedimiento sugiere cambios en las sensaciones, las percepciones, los pensamientos y los comportamientos del sujeto.

Para complementar la influencia del Talapot en "Agua Fría", se considera pertinente establecer un acercamiento de lectura en relación con los habitantes. Cada círculo de aprendizaje está custodiado por mujeres sacerdotisas, en su mayoría, quienes conocen los poderes del Cristal y el contenido de los libros sagrados; asimismo, el nombre de cada una de ellas evidencia parte de la educación general de la fortaleza.

\subsubsection{Humo de Leña}

En el proceso de búsqueda de identidad, el primer encuentro con el aprendizaje debe sentar las bases educativas y disciplinarias con el fin de facilitar la asimilación de las demás instrucciones. Esta tarea, dentro de la fortaleza, está a cargo de Humo de Leña, uno de los tutores implacables del Talapot. La educación impartida por él es la más rígida. El comportamiento de Humo de Leña es altivo, cruel, porque el círculo así lo amerita. Este tutor forma a los neófitos con una disciplina muy fuerte, dejando de lado cualquier tipo de compasión que obstaculice el aprendizaje. 
- ¿Cuántas varillas hay aquí, "Agua Fría”?

-Tres, señor. [...]

-Dos, maestro - contestó la chica poniéndose en pie, más amarilla que nunca.

-Eso es, dos. "Agua Fría”, querida, ¿cuántos son?

-Dos, señor.

- ¿Estás segura?

-Ssssí, señor...

$-i$ Y si yo te dijera que son tres?

-Entonces son tres señor. (Montero 2000: 48)

La onomástica de Humo de Leña está asociada con lo indeterminado (humo), con los restos de una fuerza transformadora (leña), pero este vínculo de términos remite a un estadio intermedio: el fuego, considerado como fuerza transformadora positiva o negativa, función que ejerce este tutor dentro del círculo.

Asimismo, la asociación del nombre desde su punto de vista etimológico, permite establecer nuevos significados que complementan su función dentro del texto. Humo proviene del término latino fumus que significa 'vapor', 'vaho' y lignum, cuyo significado es 'leño'. También puede asociarse a alheña que significa 'hacer' y se emplea con el sentido de 'destrozar', 'hacer polvo'. Entonces, la función de este tutor es destrozar todo pensamiento ajeno a los designios del Talapot, es decir, Humo de Leña esfuma los pensamientos ajenos a la ley.

\subsubsection{Duermevela}

Como mecanismo programático (Iglesias 1984) la nominación predestina al personaje haciendo de él un ser cuyo comportamiento forma parte de ese todo que es el espacio. Tal es el caso de Duermevela quien atiende a "Agua Fría" en el Círculo de Sombras. Personaje problemático desde la oposición del término dormir /velar. Es otro nombre conformado por dos partes, en una perfecta oposición de elementos dicotómicos.

Esta tutora no sólo instruye, sino que además vigila el aprendizaje de los neófitos. Como su nombre lo indica, "Vela", observa atentamente respondiendo de esta manera, lo que implica la etimología: vigilare. Sin embargo, aunque la filosofía del círculo difiera del anterior y Duermevela se muestre complaciente y abierta al diálogo, detrás de ese personaje se esconde un ser despiadado; ella es otra sacerdotisa educada dentro del castillo, por lo que, onomásticamente hablando, se identifica al personaje (Nicole 1983) con la función de 'ocultar' o 'cubrir' una imagen. Su referente será velare-velum, es decir, velo.

Aunado a toda la significación de "vela", se encuentra el otro componente del nombre, el que complementa al personaje y su función. Si la acción de dormir remite a un estado inconsciente y reposo total de los sentidos, el trabajo de Duermevela corresponde a una inversión de lo que significa este término. La tutora vela por el cumplimiento de la ley; por lo tanto, se trata de descansar lo mínimo y enseñar lo máximo, de ahí su poca disposición para el descanso. Ni ella ni sus estudiantes dedican grandes períodos al descanso.

\subsubsection{Tierra Negra}

Cada una de las tutoras ocupa un espacio dentro del Talapot y, de acuerdo con su nivel de conocimiento, queda asignado el poder y la responsabilidad. Tierra Negra adiestra a los jóvenes en los secretos de la hipnosis. Es la última estación del conocimiento, antes de obtener el sacerdocio.

Se convierte esta tutora en la posible "dadora" de conocimiento. El don otorgado es la hipnosis y, como su nombre lo indica, "Tierra", su responsabilidad es fecundar y reproducir 
ese conocimiento. Justamente la mezcla con el negro, para completar su nombre, permite asociarse a esta significación, pues este color indica poder y fuerza oscura para ser una más de las sacerdotisas -crueles- del Talapot.

Ahora, el personaje define el espacio en el que se desarrolla y dos elementos clave se pondrán en consonancia con el nombre de éste a saber: a) es un lugar completamente oscuro (Negra) y b) es el último espacio en ser accesado por los elegidos (La Tierra ocupa el último lugar de los cuatro elementos) (Diccionario de Autoridades 1979).

En este proceso de conocimiento, la joven protagonista desafía los poderes de la tutora y se arriesga a huir; Tierra Negra, sospechosa y misteriosa, intenta esclarecer el pensamiento de "Agua Fría" y no lo logra.

\footnotetext{
Tierra Negra la contempló (a "Agua Fría") escrutadoramente, como sopesando la veracidad de sus palabras.

-No te preocupes por eso -dijo al fin con cautela-. Todo está escrito en tu destino y el Cristal no puede equivocarse. (Montero 2000: 77)
}

\subsubsection{Piel de Azúcar}

Alonso Hernández (1982) afirma que los nombres propios funcionan a manera de signos con significación previa al personaje que lo porta; una vez presentado el personaje por su nombre, su actuación evoca inmediatamente en el lector otras significaciones dadas ya en la competencia socio-lingüística.

El caso de Piel de Azúcar es muy particular; si se sigue lo expuesto por Hernández, el nombre Piel de Azúcar evoca un personaje cálido, sensible, dulce y comprensivo, y forma parte de un conjunto llamado Talapot, cuyas reglas distan de lo que sería una piel de azúcar. El nombre de esta sacerdotisa corresponde a otra inversión onomástica.

\footnotetext{
Porque era ella, la terrible Piel de Azúcar, la sacerdotisa cobalto del collar de oro, imbatible en la hipnosis, cruel y poderosa. (Montero 2000: 263)

Piel de Cordero: apariencia inofensiva y bondadosa que encubre los propósitos normalmente negativos que que no corresponden con ella. (DRAE 2001: 1192)
}

Piel de Azúcar es despiadada. Todos los elementos que la rodean (sacerdotes, espacios) ejercen un poder y alejan el significado del nombre de las características del personaje. Por un lado, pareciera ser inofensiva, pero detrás de esa máscara del nombre se encuentra un ser despiadado e implacable. La función de ella es ordenar y exigir el cumplimiento de la ley. Quizás ese sea su objetivo: detrás de una "piel /azúcar" se encubren sus malvados propósitos.

\subsubsection{Océano}

El 'nombre propio' define al personaje dentro de su contexto, es decir, lo ubica en una red, la cual marca la estructura social a la que pertenece. Océano, la Gran Sacerdotisa, es quien dirige el Talapot. La ambición y el poder la han convertido en una mujer abandonada y enferma de venganza. Ni siquiera su sabiduría puede cambiar el destino de Magenta y su único afán es eliminar a la protagonista. Nuevamente, se alude al simbolismo del agua, pero no con los atributos mencionados al inicio de este artículo. Chevalier (2003) afirma que, en ciertos casos el agua puede actuar como muerte, mientras que las grandes aguas -las de un océanoanuncian pruebas y su desbordamiento son símbolo de muchas calamidades. 
La palabra Océano implica profundidad, también calma en la superficie y tormenta interna. La Gran Sacerdotisa, a pesar de imponer respeto, implícitamente impone temor, un temor asociado con la destrucción; asimismo, su nombre le permite hacerse sentir en todo el edificio. Océano no necesita estar presente físicamente para captar la atención. El simple hecho de pronunciar su nombre es señal de poder y angustia. En el proceso de conformación de identidad, Océano debe ser aniquilada. Ocurrirá cuando "Agua Fría" haya adquirido todo el conocimiento necesario para enfrentarla. Se trata de vencer sus propios temores y encontrarse con la "verdad".

En suma, no se puede concebir el Talapot sin estas mujeres; todas son tutoras y responden a una misma ley aunque, finalmente, queden devastadas por la ignorancia de no adecuarse al devenir histórico. No obstante, tienen una función importantísima en el aprendizaje de "Agua Fría", pues constituyen la primera etapa del conocimiento y a ellas se les debe la disciplina y la hipnosis que tanto favorecieron a la joven en su trayecto hacia el Norte.

A manera de mapa conceptual, se presenta, en orden ascendente, la distribución de cada una de las sacerdotisas dentro de este castillo y el objetivo que cumplen en los círculos de conocimiento.

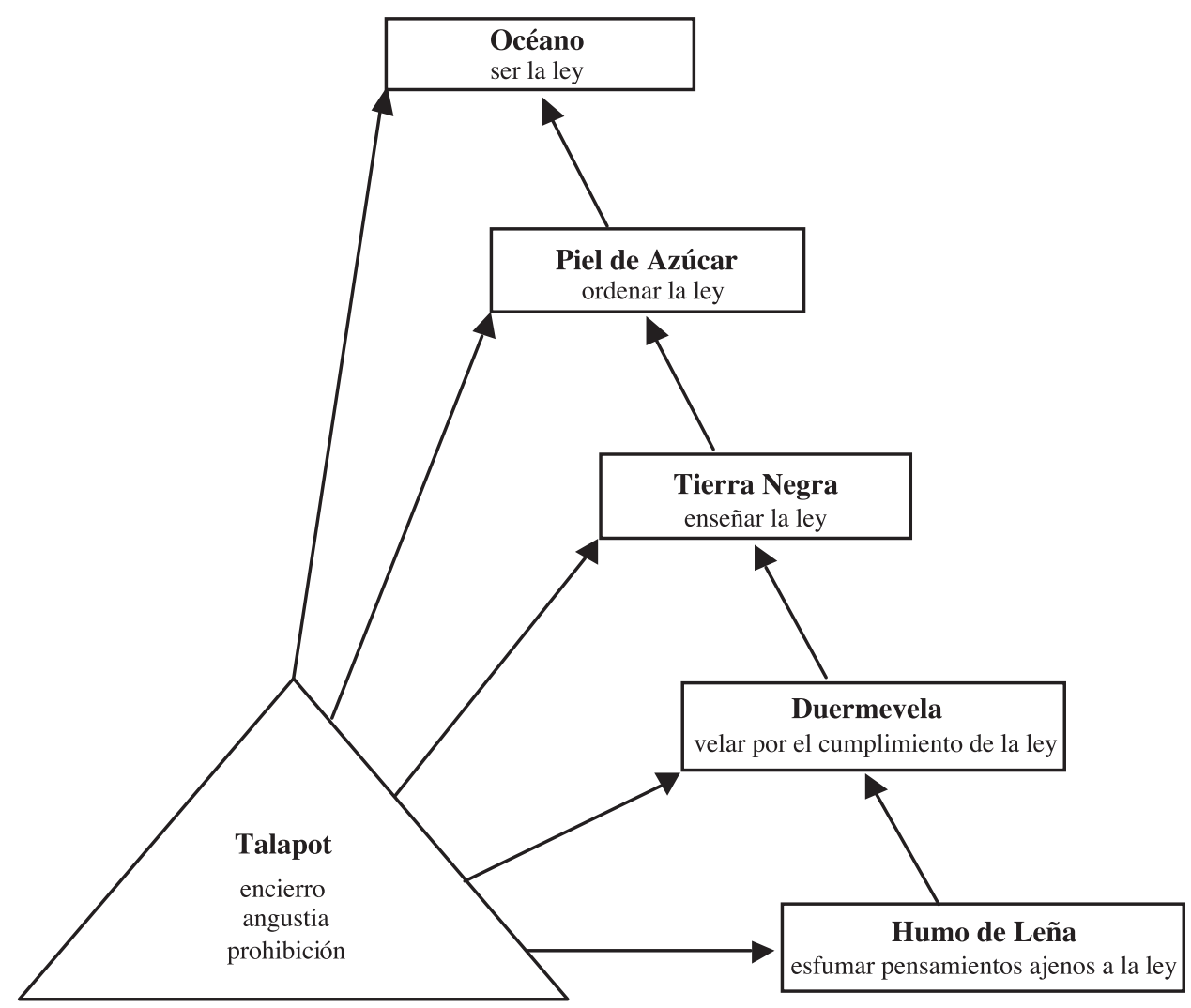

Esquema 3. Funciones de las sacerdotisas en el Talapot

Precisamente, la estructura del Talapot simboliza un concepto de matriherencia, dentro del cual los hombres no podrán acceder a los conocimientos más elevados. La genealogía de este palacio es homóloga a la genealogía patriarcal, en tanto los dos sistemas son represores y limitan las funciones de cada miembro. Por lo tanto, parte de esa búsqueda de aprendizaje 
es encontrar un sistema libre de estereotipos y patrones impuestos por una sociedad altamente nociva para el desarrollo pleno del ser humano.

En fin, "Agua Fría” recorre el palacio y llega a conocer sus más íntimos secretos. A través del periplo, logra emplearlos para sobrevivir.

\subsection{La Casa de los Grandes}

A diferencia del Talapot, la Casa de los Grandes es un lugar abierto y, como su nombre lo indica, son los Grandes, es decir Anteriores, quienes la habitan. "Agua Fría" lleva a cabo su iniciación en este lugar.

La Casa de los Grandes es para la joven uno de los espacios de mayor disfrute y placer. En Temblor, la Casa es el edificio donde habita la familia, es la institución de carácter sociocultural y recreativo; por lo tanto, adquiere importancia en relación con la totalidad de lugares que implican aprendizaje. "Generalmente la Casa de los Grandes le parecía un lugar hermoso, con sus paredes blancas, sus suelos de colores brillantes, sus patios llenos de frutales y flores" (Montero 2000: 11).

La relación Casa de los Grandes -“Agua Fría” es estrecha. La gran mentora inculca a la joven los primeros conocimientos en este espacio. Entonces, no es casual el nombre impuesto a este lugar, si se habla de grande cuando se refiere a una persona de edad avanzada o de muy elevada jerarquía, como le sucede a Corcho Quemado.

La frase "Casa de los Grandes" dentro del texto funciona como recinto de sabiduría y, por medio del recuerdo, "Agua Fría” establece el vínculo con su Anterior, al traer al presente conocimientos y consejos adquiridos allí. De ahí que espacio y personaje participen del proceso y a lo largo del viaje mantengan su vigencia.

La conjunción Casa de los Grandes-Talapot se establece a través de una dicotomía, pues ambos espacios distan mucho en su aprendizaje. Por ejemplo, cuando se asocian con el devenir de la joven establecen parámetros antagónicos en cuanto a su proceder: el castillo se convierte en el espacio que destruye los sueños, arrasa con el conocimiento adquirido y devasta toda ilusión de libertad. Por su parte, la casa transmite una sensación armónica con sus habitantes (construye al ser humano a partir de sus ideales); además, es aquel espacio donde las reminiscencias son imborrables.

[...] la casa alberga el ensueño, la casa protege al soñador, la casa nos permite soñar en paz. [...] la casa es uno de los mayores poderes de integración para los pensamientos, los recuerdos y los sueños del hombre. [...] Sin ella el hombre sería un ser disperso. (Bachelard 2002: 36-37)

El esquema siguiente recoge el conjunto de relaciones entre ambos espacios.

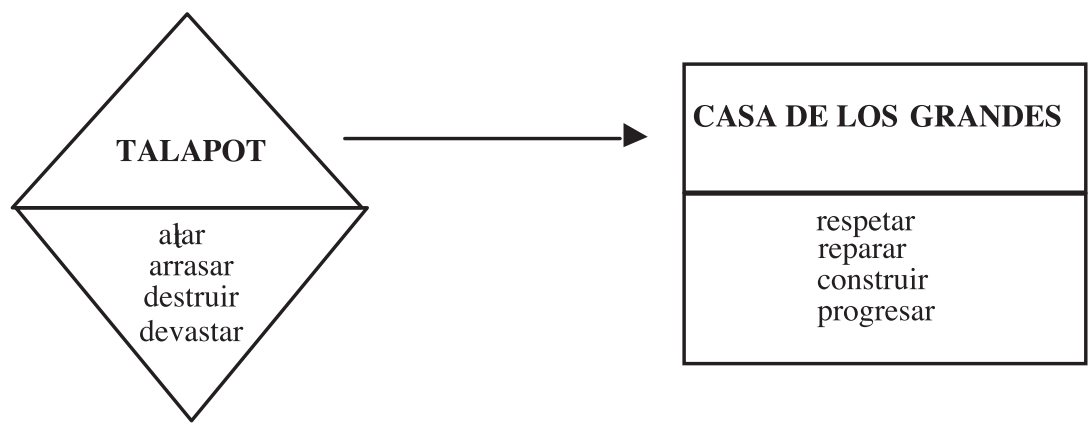

Esquema 4. Relación entre el Talapot y la Casa de los Grandes 


\subsubsection{Oxígeno}

Aunque su participación no se ubica en la Casa de los Grandes, como ocurre con Corcho Quemado, ella pertenece a la Orden que habitaba en ese lugar.

Oxígeno es la mujer más sabia, quien conoce la verdad. Este personaje señala el camino a la heroína y la conduce a encontrar esa verdad. En este proceso de conformación de identidad, Oxígeno es esencial en la vida de "Agua Fría", como se evidencia en el siguiente esquema:

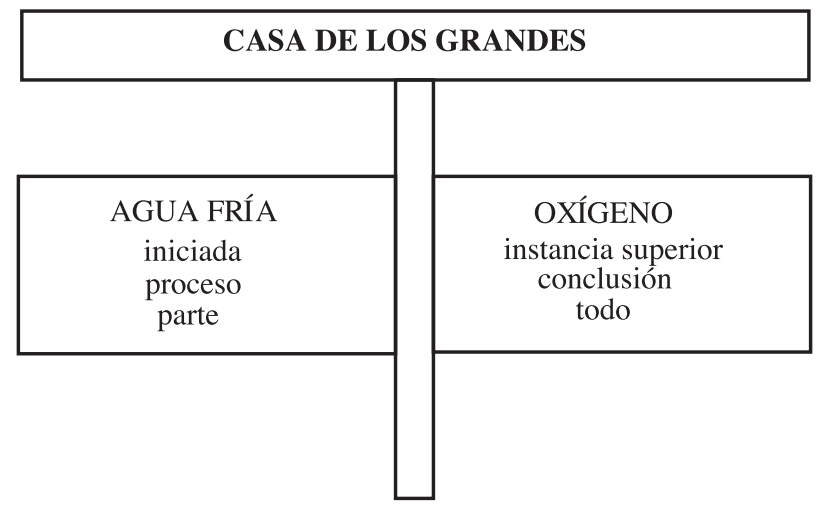

Esquema 5. Relación “Agua Fría”-Oxígeno

Nicole (1983) afirma que el nombre propio se constituye como signo, porque la atribución de un nombre propio en general no se concibe fuera de su inserción en un sistema. Es ilógico referirse a la Casa de los Grandes y no traer a colación a Oxígeno quien conforma, en pocas palabras, el sistema de la Orden. A la luz de este enunciado se analizará el onomástico de la Gran Hermana.

$\mathrm{Su}$ nombre, Oxígeno, remite a una sustancia orgánica presente en todos los seres vivos y, como tal, se convierte en un aspecto esencial. La palabra oxígeno implica 'activar' 'vigorizar' una situación que "Agua Fría" necesita para culminar con el proceso de conformación de identidad.

Ahora bien, dicho proceso no se entenderá sin este personaje, porque es Oxígeno quien aclara las dudas que impulsan a la joven a realizar el viaje: la inesperada muerte de la madre y los misterios del Talapot. Estratégicamente, la aparición de la Gran Hermana se lleva a cabo en el momento en que "Agua Fría" ya ha recorrido buena parte de ese viaje.

\footnotetext{
[...] Tenía que hacer algo, ¿no lo entiendes? Algo lo suficientemente tremendo como para que cambiara el rumbo de tu vida. Algo cuya magnitud te hiciera reflexionar, que sembrara la duda en tu cabeza. Y además necesitaba hacerlo urgentemente [...] (dice Oxígeno). (Montero 2000: 188)
}

La función de Oxígeno es conducir a una joven a encontrarse con la verdad, pero esta vez, con una experiencia que le permita llegar a un punto inicial con las herramientas necesarias.En ese sentido, es plausible establecer ejes semánticos que definan dicha función dentro del texto y confrontarlos con los de Océano. Ambas tienen un mismo pulso de fuerzas vitales, pero con distinta dirección. En primer lugar, la sacerdotisa del Talapot se encuentra rodeada de muerte, al no lograr su objetivo, su mundo se desactiva por completo con la huida de "Agua Fría" y su actitud hermética la conducen a su propia destrucción. Por el contrario, Oxígeno proporciona la esencia de la vida al activar los sueños y fomentar la búsqueda de 
la verdad. Su apertura facilita la realización personal de la joven. Se trata de una mujer completa quien muere victoriosa al saber que ha cumplido con su tarea.

El esquema siguiente expone las diferencias más marcadas entre uno y otro personaje:

\begin{tabular}{|c|c|}
\hline OCÉANO & OXÍGENO \\
\hline $\begin{array}{c}\text { muerte } \\
\text { desactivar } \\
\text { hermetismo }\end{array}$ & \\
\end{tabular}

Esquema 6. Diferencias entre Océano y Oxígeno

\subsection{Renacimiento}

El término Renacimiento sugiere, desde el punto de vista histórico, una época de cambio. Se trata de un movimiento intelectual que produce una nueva forma de pensar, con respecto a la concepción del mundo y del ser humano. Constituye una revolución espiritual: se cambia lo religioso y lo divino de la Edad Media por lo secular, lo humano y lo terrenal de la Edad Moderna.

Renacimiento significa renacer del modo de vida de la antigüedad: la de los griegos y los romanos. Los hombres quisieron conocer, juzgar y comprobar por sí mismos cómo eran las cosas. Los intelectuales buscaron respuestas en las ciencias y el pueblo, en las aventuras y las exploraciones. En la Edad Media, la preocupación del hombre fue la salvación del alma, lo sobrenatural. En la época moderna, el interés es por el ser natural. Por eso, valoraron al ser humano. Estudiaban la anatomía, expresaban en el arte la belleza corporal; en fin, buscaron disfrutar de la vida terrenal.

En ese sentido, se originó una cultura antropocéntrica, en que pensadores y escritores desarrollaron ideales del humanismo, dedicados al perfeccionamiento y al bienestar del hombre. Renacimiento, en el texto, constituye ese lugar que valora desde otra perspectiva la vida. No es el espacio cerrado, acaparador e impositivo como el Talapot, sino el renacer a una nueva vida.

La palabra Renacimiento, desde el punto de vista toponímico, forma parte del grupo de ecónimos (Garita 2001) -nombres de poblados- del texto; su origen no remite a alguna palabra existente en el pueblo, pero sí se puede establecer su relación con la etimología. El término es sugestivo: renasci, significa 'reaparecer', 'renacer'. Renacer a una nueva vida con otra perspectiva y reaparecer -en el caso de "Agua Fría"- en un grupo cuyos ideales se comparten y se lucha por la misma causa.

El aprendizaje de "Agua Fría" en Renacimiento la hace comprender el valor del trabajo por sí misma. Este espacio le proporciona seguridad e independencia. Está conformado por opositores de la Ley; por eso, para "Agua Fría” la estancia en Renacimiento es placentera.

[...] Renacimiento se componía de un conjunto de valles trepados a los hombros de un imponente circo de montañas. Un paraíso remoto en el que los dos centenares de proscritos vivían una existencia rural y sosegado [...] Reencontró así “Agua Fría” la esencia misma del mundo, ese empeño remoto y ciego de las cosas [...] Se había integrado al fin a Renacimiento. A decir verdad, más que integrarse, lo que deseaba ahora era fundirse en esa vida colectiva. (Montero 2000: 134, 137,148)

La 'toponimia' puede utilizar connotaciones que lleven a establecer una asociación de elementos culturales o lingüísticos cuyo valor sea imprescindible para entender el funcionamiento del espacio en el que se desarrolla ese personaje. Renacimiento connota un 
aprendizaje nuevo, libertad para desenvolverse; es un bautismo / baño para purificarse de las ignominias del Talapot y una visión diferente de la existencia.

\subsubsection{Enigma}

La onomástica de este personaje cumple con lo que Nicole (1983) establece, pues permite aclarar la "presencia" y el "desarrollo" de los personajes.

Enigma, como su nombre lo indica, artificiosamente es la líder de la comarca, una mujer sabia cuyo poder y autoridad estriba en poseer el conocimiento de la cinestesia.

\footnotetext{
Se llamaba Enigma y era la líder de la comunidad. Porque, aunque en Renacimiento se vivía un ensueño igualitario y proclamaban que carecían de jefes y que no existía discriminación alguna entre los sexos, lo cierto era que, de un modo tácito todos admitían la autoridad de Enigma". (Montero 2000: 136. El subrayado es nuestro)
}

Otra mujer se une a esta amalgama de líderes en cada lugar visitado por la joven. El método utilizado por Enigma, al enseñar la cinestesia, enigmáticamente, produce en "Agua Fría" resultados sorprendentes, que la llevan a cuestionar la existencia desde un punto de vista distinto, como lo había hecho hasta ahora.

La aventura vivida en Renacimiento propicia la sabiduría para retomar el viaje de "Agua Fría", desde una perspectiva diferente. Enigma se convierte en una mentora quien le aporta a la heroína valor y confianza en sí misma. Lo que en un inicio parecía ser misterioso en Enigma, pasa a ser provechoso en "Agua Fría".

\subsubsection{Torbellino}

El vocablo alude a un remolino de viento, cuya intensidad es variable; este fenómeno natural puede ser vinculado, en términos metafóricos, a una persona viva e inquieta. En el caso de Torbellino, el texto no esclarece el comportamiento, ni las intensiones de ella; sin embargo, destaca el valor humano y la entereza para salvarle la vida a "Agua Fría".

Desde el punto de vista narrativo, la identificación del personaje funda el relato y orienta la lectura en la expectativa de un destino. Torbellino rescata a la joven de las inclemencias del Desierto y es quien la introduce en Renacimiento. La muerte se acercaba a "Agua Fría" y Torbellino aparece heroicamente dándole un giro total a su destino.

\footnotetext{
[...] Los ojos de "Agua Fría" se humedecieron y las hierbas fantasmales se emborronaron tras el velo de lágrimas, tan próxima ya a la oscuridad final. Pero el perro seguía ladrando y la muchacha sintió que algo se movía junto a ella; algo que la tocaba, que la volvía boca arriba, que la palpaba; unas manecitas pequeñas, calientes, sudorosas, unas manos minúsculas que la sujetaban por las muñecas y la arrastraban por el suelo. Súbitamente el aire se hizo más dulce, más liviano. Quizá la muerte sea esto, se dijo "Agua Fría”. Y abrió los ojos y contempló un cielo intenso y un sol glorioso y deslumbrante. (Montero 2000: 129)
}

Dos ejes semánticos pueden establecer la relación de Enigma y Torbellino con "Agua Fría": conocimiento y sentimiento. Asociados a la personalidad de la protagonista dan lugar a una nueva experiencia y a una enseñanza.

\begin{tabular}{|c|c|c|}
\hline Personaje & Enigma & Torbellino \\
\hline Conocimiento & Astuta & Dedicada \\
\hline Sentimiento & Misteriosa & Bondadosa \\
\hline
\end{tabular}

Esquema 7. Ejes semánticos de Enigma y Torbellino 
La actitud de Enigma está siempre a la defensiva. Astutamente sabe conducir a su comarca, mientras que Torbellino es dedicada y esforzada en aprender. El aspecto sentimental en Enigma, como su nombre lo indica, no se deja ver desde el principio. Permanece como un misterio dentro de la mente de "Agua Fría", en tanto que Torbellino es bondadosa y entregada hacia la joven.

\subsection{Desierto}

Según la tradición semítica, el Desierto es un lugar empleado para purificar el espíritu y el cuerpo. En Temblor, es el espacio que sirve de transición entre el Talapot y Renacimiento.

Las grandes trayectorias de los pueblos antiguos se hacían a través del desierto, con el fin de purificarse o mejorar su raza; por ejemplo, Moisés conduce al pueblo de Israel por el desierto, al lugar prometido por Yahvé (Libro del Éxodo). Quienes perecen en él demuestran que no son aptos para el desarrollo de la nueva generación. Justo al salir del Desierto, Respy abandona a "Agua Fría" y ésta resurge a una nueva vida en Renacimiento. El Desierto se constituye en el espacio para purgar, producto de la salida del Talapot.

[...] Transcurrieron así los días, en el desaliento de un paisaje que siempre parecía el mismo. El horizonte se extendía en torno a ellos como una lámina de temblorosa gelatina. Apenas les quedaba agua y los deshidratados caballos ya no servían de montura. (Montero 2000: 121)

\subsubsection{Koalá}

Koalá aparenta ser una mujer egoísta. La relación con "Agua Fría” se desarrolla mediante un intercambio de intereses; mientras una se ambiciona por el oro, la otra necesita agua para seguir viviendo.

El destino de Koalá es negativo. Es invadida por la bruma y tiene una "muerte verdadera". Es la única habitante del Desierto. Aunque su participación no se prolonga en el texto, ella es importante porque es quien proporciona el elemento vital en el lugar. Su nombre remite a los koalas australianos: mamíferos aborícolas marsupiales. No obstante, estableciendo relación con su desempeño, implícitamente, Koalá es perezosa, característica de estos animales; además, es tranquila y permanece en el mismo lugar, como lo hacen los koalas en los árboles, que se mantienen allí durante días.

-Yo me llamo Koalá y este pozo es mío. Y no pienso explicaros el significado de mi nombre, entre otras cosas porque no me lo ha dado ningún Anterior y porque, además, el Cristal me importa un cuerno [...] Quien no paga no bebe. Es la ley del desierto. (Montero 2000: 123)

El valor del Desierto en relación con Koalá es signo de decadencia, angustia y sofocamiento. Tras el inmenso calor y la desesperación de atravesar este lugar se encuentra una mujer que caducará en esas condiciones, pues su actitud le impedirá poner a salvo su vida.

\subsection{Rocas Negras}

Temblor responde a una estructura matriarcal. Cada etapa de "Agua Fría" comprueba los esquemas con los que ella fue educada: los hombres son considerados inferiores. Por su naturaleza, les corresponde matar; en cambio, las mujeres están privilegiadas por su capacidad de procrear y ser las ejecutoras de la ley. 
La presentación de cada uno de los distintos espacios, en relación con estos esquemas de vida, conduce a un cuestionamiento en la misma protagonista, pues ninguno de los habitantes conoce la respuesta que ella necesita. Esto pone en entredicho la "eficacia" del gobierno y la forma de concebir la existencia; ninguno tiene la respuesta para solucionar el problema de la esterilidad.

En cuanto a la toponimia, y apuntando a lo que plantea Garita (1998), uno de los factores que determinan el nombre del lugar geográfico es la interacción del medio ambiente. Rocas Negras es un ecónimo que alude a un componente del ambiente. Se trata de un macizo montañoso cuyo efecto, al verlo durante el día, se asocia al color negro: un término que obedece a las características de la región.

Es el único lugar que cambia los patrones establecidos en la joven. Sus principios de vida son patriarcalistas. Ellos obedecen a valores impuestos por su máxima autoridad: un hombre. Particularmente, "Agua Fría" encuentra un detalle que llama poderosamente la atención: todos mueren de "muerte verdadera", es decir, nadie perdura en el recuerdo y no se sienten afectados. Sin embargo, igual que el resto, la preocupación por la paulatina destrucción del mundo los aqueja.

Rocas Negras aporta a ese proceso la seguridad y el valor que la joven necesita para regresar al Talapot. Metafóricamente, como una roca bien formada se dispone "Agua Fría" a emprender su trayectoria hacia el palacio y enfrentarse con Océano. En ese sentido y asociado a la onomástica, Rocas Negras es el lugar en el que la heroína comprende el sentido de la existencia. En Rocas Negras, tres nombres masculinos sobresaldrán: Bala, Zao y Dogal. Ellos son quienes establecen un vínculo muy estrecho con la heroína y participan activamente en esta búsqueda de la verdad.

\subsubsection{Bala}

Su condición de jefe le permite decidir sobre el destino de los habitantes y la estadía de la joven en Rocas Negras.

El término "bala" alude a una persona rápida, sagaz. Precisamente, la máxima autoridad de Rocas Negras es un hombre con esa cualidad. Por tratarse de un pueblo violento y guerrero, el jefe debe actuar con mucha rapidez y estrategia, como una bala, y así lograr su objetivo: “[...] Yo mando. Yo soy el jefe Bala. Soy el gran jefe Bala[...]" (Montero 2000: 202).

De acuerdo con Nicole (1983), el nombre evoca la imagen de la persona que lo porta en un contexto dado. Bala se asimila a la figura de un indio cuya responsabilidad es su pueblo; por lo tanto, es un hombre sabio, fuerte, misterioso y con poder de decidir: la vida o la muerte.

[...] Siento el fin de nuestro pueblo en mis huesos, del mismo modo que el cervato ventea la muerte en el olor a gato salvaje, aun sin conocerlo. El mundo está lleno de nuevos peligros, y la extranjera parece saber más de esos peligros que nosotros mismos. No me parece prescindir ahora de su presencia y de sus extraños conocimientos. [...] El gran jefe Bala ha decidido. Bala os dice: perdonemos a la mujer y la mantendremos con nosotros. (Montero 2000: 219-220)

El jefe es un indio con costumbres asociadas a las creencias de su pueblo. Su poder se desarrolla en pro de los que confían en él. Bala no sólo es un hombre. Es el jefe de la tribu y, como tal, debe tener poder mental, en tanto convenza a su gente para actuar, y poder social, porque se trata de guiar al pueblo respetando sus costumbres y tradiciones. 


\subsubsection{Zao}

Este personaje cumple un papel preponderante en la vida de "Agua Fría". Primero, porque es el padre del hijo que ella espera y, segundo, porque se trata del hombre que salvó su vida.

\footnotetext{
-Acepto el reto. Yo pelearé [...] Al ser herido, Zao había perdido la maza, pero aún tenía la jabalina. Era bueno con la jabalina [...] Cegado por el dolor y la lluvia, confuso y aturdido, Zao alzó la jabalina y Urr se ensartó en ella [...] Zao había sido herido por ella. ¡Zao había matado por ella! (Montero 2000: $220,223,224)$
}

La onomástica literaria puede utilizar además de las características significantes, las connotaciones que pueden afectar a ciertos términos particulares, las cuales serán reconocidas por los usuarios que posean el código de referencia.

En ese sentido, Zao es una palabra griega cuyo significado es "para mí vive"; según lo anterior, el término puede relacionarse con la joven, puesto que él vivirá por ella y en ella: es el padre de su hijo y el ser que se entregó a cambio de su libertad.

Entonces, Zao será entendido como "vida" en el sentido de ser próspero, de consagrar la vida a alguien (a "Agua Fría") de modo que la vida dé como resultado que se beneficie a alguien.

\subsubsection{Dogal}

La onomástica literaria afirma que el nombre configura la imagen ideal del portador. Dogal, el hijo mayor de Bala, debe cumplir con todos los mandatos de su padre. La imagen que el nombre le otorga es la de un hombre fuerte, cuya responsabilidad está en proteger la tribu.

Dogal es sinónimo de lazo. También puede emplearse el término cuerda, pues se trata del dogal con que atan a las caballerías por el cuello. La función de este personaje es servir de guía. Tratándose del hijo del gran jefe es pertinente aludir a él como un joven a quien se le heredará el poder. Por lo tanto, Dogal, dirigirá la tribu cuando Bala muera. Será como una cuerda sirviendo de guía. "La partida se componía de veintitrés personas, con Dogal como caudillo. [...] Puesto que los tiempos se acababan y el viejo orden estaba agonizando [...]" (Montero 2000: 241).

La onomástica, como se ha dicho, sirve para ubicar al lector y, en nuestro caso, analizar de qué manera se relacionan los personajes con el objetivo de la protagonista.

\section{Consideraciones finales}

A excepción de los nombres de los líderes de cada lugar, es importante destacar que muchos de ellos morfológicamente son sustantivaciones, sea por término: sustantivo + preposición + sustantivo, o por aposición: sustantivo + sustantivo. De esta manera, el segundo nombre será un adjetivo del primero. Las mujeres tutoras del Talapot evidencian esta estructura: Piel de Azúcar, Duermevela. Lo que se pretende es ampliar la connotación del nombre y brindarle al personaje más protagonismo, sin opacar el de su líder. La presencia, tanto de los personajes como de los lugares, se debe a que cumplen un fin dentro del proceso de "Agua Fría"; las funciones de cada uno otorgan un tipo de conocimiento a la heroína y amplían su experiencia, acercándola hacia la verdad, hacia su camino.

La onomástica presenta una amalgama de posibilidades en el recorrido de la heroína, abriendo en cada etapa un camino para lograr el objetivo. No es casualidad el nombre de los espacios y personajes, sino que sustenta parte de todo el proceso de conformación de identidad. 
En virtud de mostrar la experiencia de "Agua Fría" en relación con la señal de la onomástica y la toponimia, se concluye lo siguiente:

a) Los espacios permiten a la joven evolucionar de manera tal que la interacción: personaje / lugar la conduzcan a la verdad. En ese sentido, la toponimia del Talapot, Casa de los Grandes, Renacimiento, Desierto, y Rocas Negras constituyen señales que caracterizan el proceso de conformación de identidad.

b) Los tutores del Talapot disciplinan a la protagonista inculcándole la obediencia y el respeto como forma de vida. La onomástica de cada uno refleja ese comportamiento y promueve un significado, tanto del palacio como de los habitantes.

c) La Casa de los Grandes, por el contrario del Talapot, forma mediante convicción y no imposición. Por lo tanto, como su nombre lo indica, es el lugar apacible, cálido... únicamente para los Grandes maestros: Oxígeno y Corcho Quemado.

d) En Renacimiento, "Agua Fría" participa de un nuevo esquema de vida, se involucra en las enseñanzas de los habitantes e intercambia los conocimientos aprendidos en el Talapot. Se trata de renacer hacia una perspectiva distinta enfocada en su identidad, en el crecimiento físico, emocional y espiritual. A través de la onomástica, se visualizan esas relaciones interpersonales de la heroína con los personajes, permitiendo establecer nexos entre ellos más allá de lo evidente. Se tiene, entonces, el vínculo Enigma-“Agua Fría”, por medio del aprendizaje; el acoplamiento Mo-“Agua Fría”, por medio del sentimiento y Torbellino- "Agua Fría", por la amistad y el agradecimiento.

Finalmente, en Rocas Negras, se le enseña a la protagonista la esencia de la vida y se concluye con su formación, convirtiéndola en un ser maduro, identificado con su contexto, capaz de vencer los miedos y dudas. Basta mencionar la armonía desarrollada con Bala y Zao, quienes por medio de su nombre connotan valor, entrega y verdad. "Agua Fría" consciente de su propio destino acepta esposarse con Zao, de ahí que la relación onomástica: Zao-“Agua Fría” sea una mezcla de fuerza (él) y vitalidad (ella).

\section{Notas}

1. La onomástica literaria es el estudio del funcionamiento textual de los nombres propios. Es la teoría del nombre. Un campo relativamente restringido de observaciones puntuales, en el cual se pone en evidencia, a menudo, a través de la etimología, el valor semántico de los referentes del personaje o del lugar de los autores particularmente sensibles a la escogencia de sus significados".

2. Un texto no sólo existe, consiste, reproduce, se deja leer o escribir, sino que se trabajó por la complejidad del nombre propio".

3. Coincidimos con Garita en considerar la toponimia como una vertiente del estudio onomástico.

\section{Bibliografía}

Alonso Hernández, José Luis. 1982. “Onomástica y marginalidad en la picaresca”. Imprévue. Etudes Sociocritiques. 1: 203-233. 
Biederman, H. 1993. Diccionario de Símbolos. Barcelona: Editorial Paidós.

Braunstein, Néstor. Falta el año. Psiquiatría, teoría del sujeto, psicoanálisis (hacia Lacan). $6^{\text {ta }}$ Edición. México: Siglo XXI editores.

Chevalier, Jean et al. 2003. Diccionario de Símbolos. Barcelona: Editorial Herder.

Constenla Umaña, Adolfo. 1995. “Onomástica Guatusa”. Lingüística Chibcha. 14: 41-88.

Corominas, J. y José A Pascual 1993. Diccionario Crítico Etimológico Castellano e Hispánico. Editorial Gredos. Madrid, 1993. Vol. I, II, III, IV,V.

Diccionario de Autoridades. Real Academia Española. 1979. Madrid: Editorial Gredos.

Diccionario Básico VOX: latin-españollespañol-latino. 1993. Barcelona: Editorial Bibliograf, S.A.

Diccionario de la Lengua Española: Real Academia Española. 2001. Vigésima segunda edición. Tomo 1 y 2.

Diccionario Manual VOX: griego-español. 1994. Barcelona: Editorial Bibliograf, S. A.

Garita Hernández, Flor. 1994. "Clasificación de los topónimos de la provincia de Cartago procedentes de nombres comunes según clase o función gramatical". Revista Káñina.28 (1): 99-103.

1998. “Toponimia indígena de la provincia de Guanacaste, Costa Rica”. En Revista de Filología y Lingüística. 24 (2): 177-206.

2000. "La influencia extranjera en la toponimia costarricense". Revista de Filología y Lingüística. 26 (2): 139-160.

2001a. "Algunos topónimos indígenas de la provincia de Puntarenas, Costa Rica. Revista de Filología y Lingüística. 27 (2): 157-176.

2001b. "Los patrones culturales en la formación de litónimos de Costa Rica". Revista Káñina. 25 (1): 75-89.

Iglesias, Ángel. 1984. "El simbolismo de los nombres en Miau. Historia gatuna de Madrid”. Bolletin Hispanique. 86 (3-4): 379-402.

Montero, Rosa. 2000. Temblor: Barcelona: Editorial Seix Barral.

Nicole, Eugene. 1983. "L' onomastique littéraire”. Poétique. (54): 233-253. 